\title{
Anti-CD19 Monoclonal Antibody XmAb5574
}

National Cancer Institute

\section{Source}

National Cancer Institute. Anti-CD19 Monoclonal Antibody XmAb5574. NCI Thesaurus.

Code C95768.

An Fc engineered, humanized anti-CD19 monoclonal antibody directed against the B-cellspecific membrane protein CD19 with potential immunostimulating and antineoplastic activities. Anti-CD19 monoclonal antibody XmAb5574 targets and binds to CD19, thereby depleting and eliminating CD19-expressing B-cells. The modified Fc region of XmAb5574 increases binding affinity to Fc-gamma receptors of effector cells and thereby enhances antibody-dependent cellular cytotoxicity (ADCC) and antibody-dependent cell-mediated phagocytosis (ADCP). CD19 is widely expressed during B-cell development, from pro-Bcell to early plasma cell stages. 